\title{
Effect of Ultrasound on the Mechanical Properties of Electrodeposited Ni-SiC Nano Composite
}

\author{
Gobinda Gyawali, Sung-Hun Cho, Dongjin Woo* and Soo Wohn Lee**† \\ Department of Metallurgy and Materials Engineering, Sun Moon University, Asan, Korea \\ *Korea Institute of Construction Materials, S. Korea \\ **Department of Environmental Engineering, Sun Moon University, Asan, Korea
}

(Received June 22, 2010 : Received in revised form August 7, 2010 : Accepted August 7, 2010)

\begin{abstract}
Nano sized SiC particles $(270 \mathrm{~nm})$ are easily agglomerated in nickel sulfamate electrolytic bath during a composite electrodeposition process. The agglomeration of nano particles in composite coatings can significantly reduce the mechanical properties of the composite coatings. In this study, Ni-SiC nano composite coatings were fabricated using a conventional electrodeposition process with the aid of ultrasound. Nano particles were found to be distributed homogeneously with reduced agglomeration in the ultrasonicated samples. Substantial improvements in mechanical properties were observed in the composite coatings prepared in presence of ultrasound over those without ultrasound. Ni-SiC composite coatings were prepared with variable ultrasonic frequencies ranging from $24 \mathrm{kHz}$ to $78 \mathrm{kHz}$ and ultrasonic powers up to 300 watts. The ultrasonic frequency of $38 \mathrm{kHz}$ with ultrasonic power of 200 watt was revealed to be the best ultrasonic conditions for homogeneous dispersion of nano $\mathrm{SiC}$ particles with improved mechanical properties in the composite coatings. The microstructures, phase compositions, and mechanical properties of the composite coatings were observed and evaluated using SEM, XRD, Vickers microhardness, and wear test. The Vickers microhardness of composite coatings under ultrasonic condition was significantly improved as compared to the coatings without ultrasound. The friction coefficient of the composite coating prepared with an ultrasonic condition was also smaller than the pure nickel coatings. A synergistic combination of superior wear resistance and improved microhardness was found in the Ni-SiC composite coatings prepared with ultrasonic conditions.
\end{abstract}

Key words composite coatings, ultrasound, agglomeration, microhardness, wear.

\section{Introduction}

Codeposition of nano-sized hard ceramic particles like $\mathrm{SiC}, \mathrm{WC}$, diamond, $\mathrm{Al}_{2} \mathrm{O}_{3}, \mathrm{TiO}_{2}, \mathrm{SiO}_{2}$ etc. in metal matrix has been reported due to the superior properties of the composite over pure metal deposit. ${ }^{1-6)}$ The uniform dispersion of the second phase hard ceramic particles leads to the improvement in mechanical properties, tribological properties, corrosion resistance, anti-oxidation as well as increased microhardness in the composites. ${ }^{7}$ Electrodeposited Ni matrix composite containing fine ceramic particles are in wide demand on advance materials market. One of the most widely applied composite coatings is Ni-SiC system. Being its major field of application in the automotive industries, it is used to reduce the wear on the side of cylinder. ${ }^{8)}$ Many studies have been made on nickel based $\mathrm{SiC}$ nano composite by electrodeposition technique. ${ }^{9)}$ The previous literatures also suggest that the codeposition of nano sized particles in the metal matrix is more difficult than that of the micron sized particles. The main difficulty is the agglomeration of nano particles during the electro-

\footnotetext{
${ }^{\dagger}$ Corresponding author

E-Mail : swlee@sunmoon.ac.kr (S. W. Lee)
}

deposition. ${ }^{10)}$ The properties of the composite coatings depend upon many variables, particularly on the nature and content of SiC particles dispersed in the Ni-matrix. Many experimental parameters like current type, current density, electrolyte composition, temperature, electrode/electrolyte movements, presence of additives etc. affect the codeposition of Ni-SiC system. ${ }^{11)}$ Use of ultrasound during electrodeposition process has also been reported in previous literatures in order to reduce the agglomeration of nano particles and their homogeneous distribution in metal matrix. ${ }^{12)}$

The aim of the present work is to fabricate the Ni-SiC composite coatings by electrodeposition technique in presence of ultrasound and to evaluate the properties of composite over conventional electrodeposits without any aid of ultrasound. The properties of the electrodeposited composite coatings were evaluated by Field Emission Scanning Electron Microscope (FESEM), Scanning Electron Microscope (SEM), X-ray diffraction (XRD), wear and Vickers microhardness test.

\section{Experimental Procedure}

All electroplating experiments were conducted in a 1000 
Table 1. Electrolytic bath composition and operating conditions.

\begin{tabular}{cc}
\hline $\mathrm{Ni}\left(\mathrm{NH}_{2} \mathrm{SO}_{3}\right)_{2}\left(\mathrm{gl}^{-1}\right)$ & 300 \\
$\mathrm{NiCl}_{2}\left(\mathrm{gl}^{-1}\right)$ & 10 \\
$\mathrm{H}_{3} \mathrm{BO}_{3}\left(\mathrm{gl}^{-1}\right)$ & 40 \\
$\beta-\mathrm{SiC}\left(\mathrm{gl}^{-1}\right)$ & $5-20$ \\
$\mathrm{CTAB}\left(\mathrm{gl}^{-1}\right)$ & 0.24 \\
Sod. dodecyl sulfate (mol/l) & $1.4 \times 10^{-3}$ \\
Temperature $\left({ }^{\circ} \mathrm{C}\right)$ & 50 \\
$\mathrm{pH}$ & 4 \\
Current type & $\mathrm{DC}$ \\
Current density $\left(\mathrm{mA} / \mathrm{cm}{ }^{2}\right)$ & 60 \\
Stirring rate $(\mathrm{rpm})$ & 250 \\
Ultrasonic Frequency $(\mathrm{kHz})$ & 24,38, and 78 \\
Ultrasonic power $(\mathrm{w})$ & $100-300$ \\
\hline
\end{tabular}

$\mathrm{ml}$ glass Beaker. The plating electrolyte was made using Ni-Sulfamate (Purity $\geq 90 \%$, Samchun pure chemical Co., LTD., Korea) of which concentration and compositions are listed in Table 1. Pure Ni-balls inside a titanium basket was used as anode while SUS 304 stainless steel sheet of exposed area $2 \mathrm{~cm} \times 3 \mathrm{~cm}$ was used as cathode. Cathode was ultrasonically cleaned for 5 minutes before plating. The cathode and anode were placed vertically in electrolytic bath and were separated about $5 \mathrm{~cm}$ apart from each other. Direct Current (DC) with a current density $60 \mathrm{~mA} / \mathrm{cm}^{2}$ was applied during electrodeposition process and the electrolyte was stirred about $250 \mathrm{rpm}$ with magnetic stirrer. In case of ultrasonic electrodeposition, the whole system was immersed inside the ultrasonic chamber containing water.

After the electrodeposition, the samples were cleaned by running distilled water followed by ultrasonic cleaning for 5 minutes in order to remove loosely adsorbed particles and then subjected for further analysis. Microstructures, phase compositions, mechanical properties such as wear and microhardness were analysed and evaluated with FESEM (JSM - 6700F, JEOL, Tokyo, Japan), SEM (JSM6400, JEOL, Tokyo, Japan), XRD (Rigaku DMAX 2200, X-Ray Diffractometer, Japan), wear (Plint TE77 Tribometer, UK) and Vickers microhardness (Buehler Ltd., USA). Vickers microhardness was measured by applying $0.98 \mathrm{~N}$ loads for 10 seconds on five different places of a sample cross-section and the values were averaged. Wear and friction coefficients were measured simultaneously by applying $2 \mathrm{~N}$ loads for the duration of 10 minutes with the frequencies of $10 \mathrm{~Hz}$. $\mathrm{Si}_{3} \mathrm{~N}_{4}$ ball (SN101C) of specific diameter 0.5 " was used as counterpart during wear test.

\section{Results and Discussion}

SEM image of $\beta$-SiC nano powder used in the composite coating is shown in Fig. 1(A). It shows the agglomeration even in the dry condition due to it's high specific surface area. Surface structure of the pure Ni electrodeposit is shown in Fig. 1(B) which is characterized by the large triangular shaped grains.

The Ni-SiC composite coating prepared under ultrasonic condition shows the smooth surface as shown in Fig. 1(D) compared to conventional electrodeposition process without aid of ultrasound Fig. 1(C). The smooth surface of the composite in presence of ultrasound is due to the ultrasonic cavitation effects that prevent the regular grain growth and origination of many nucleation sites.

Fig. 2 shows the cross-section images of Ni-SiC com-
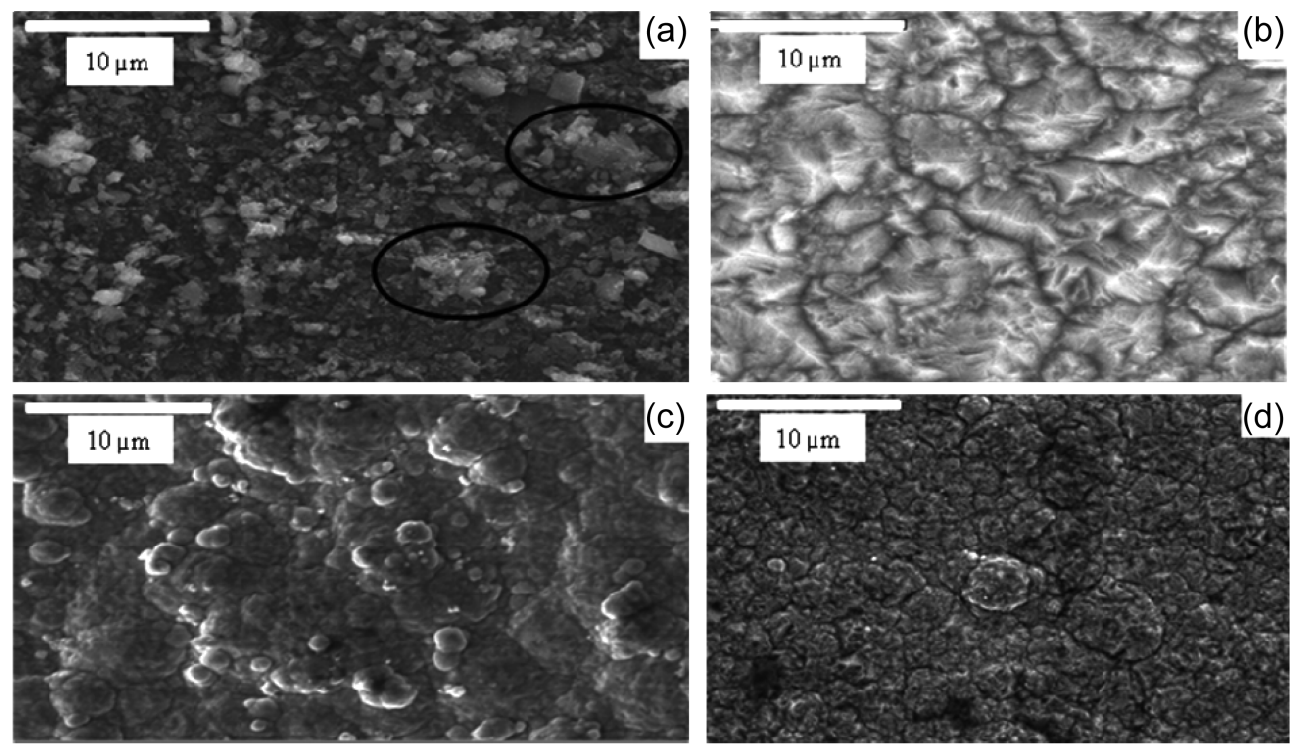

Fig. 1. SEM images of (a) $\beta$-SiC nano powder, (b) Surface morphology of Pure Ni electrodeposit, (c) Surface morphology of Ni-SiC without ultrasonic treatment and (d) Surface morphology of Ni-SiC with ultrasonic treatment. 

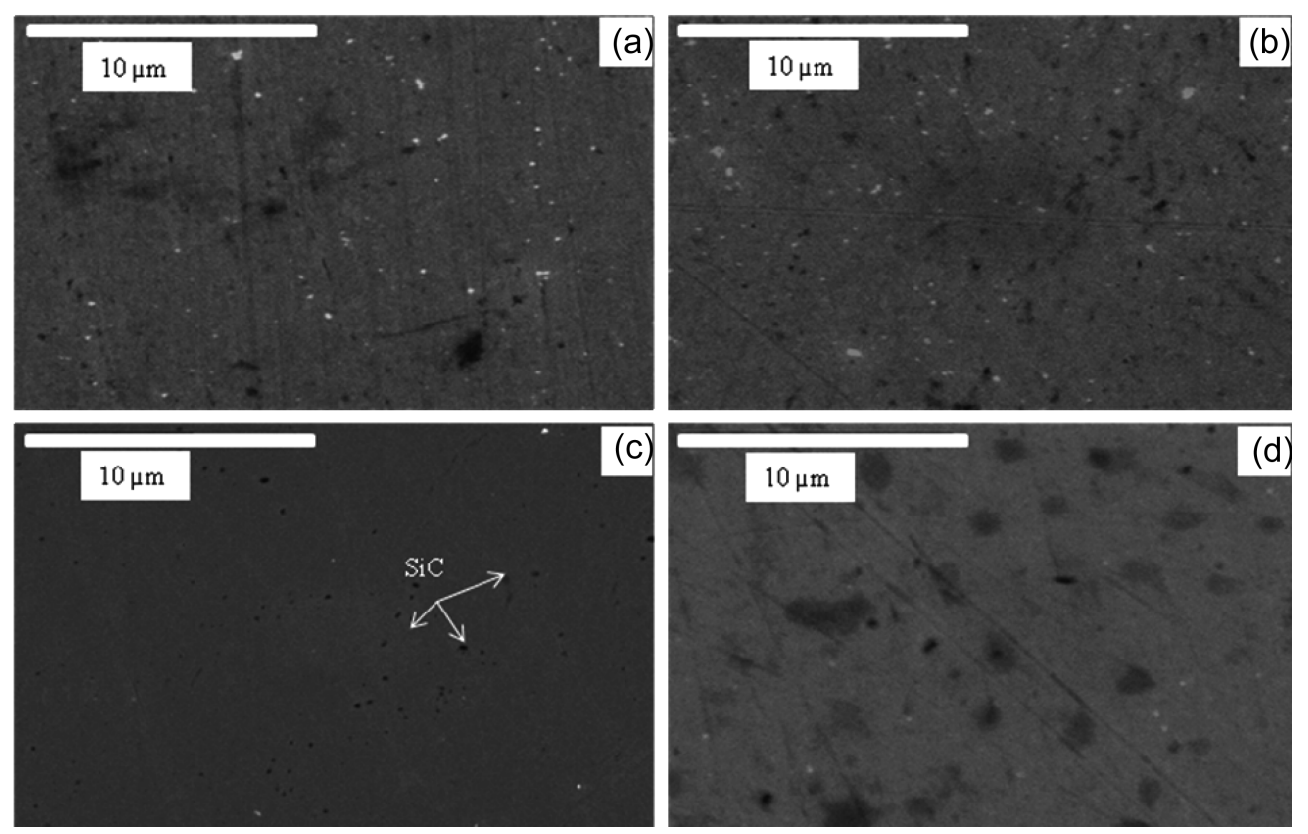

Fig. 2. Cross-Sectional SEM images of Ni-SiC composite coatings prepared: (a) without ultrasound, (b) with ultrasonic frequency (24 kHz), (c) with ultrasonic frequency $(38 \mathrm{kHz})$ and (d) with ultrasonic frequency $(78 \mathrm{kHz})$.

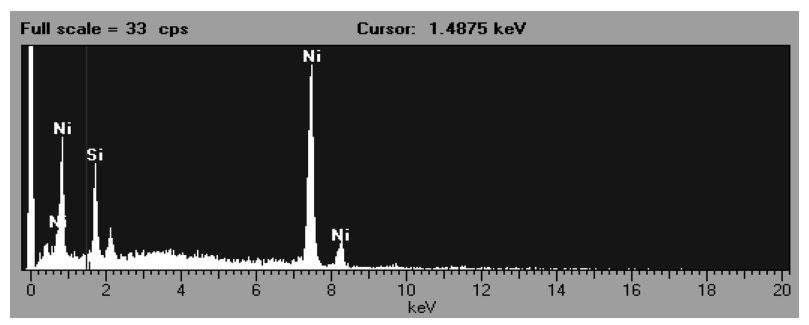

Fig. 3. EDX spectrum of the cross-section of $\mathrm{Ni}-\mathrm{SiC}$ composite coating.

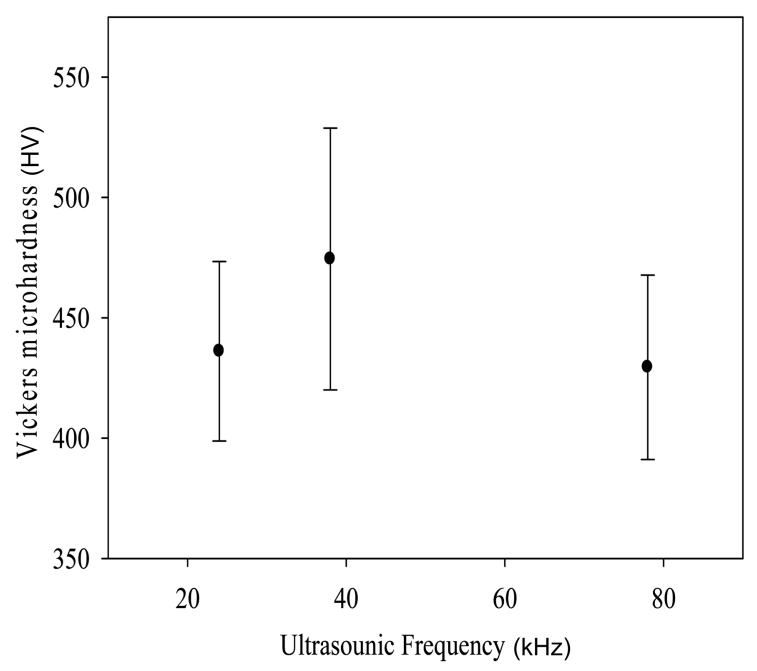

Fig. 4. Vickers microhardness of Ni-SiC composite at different ultrasonic frequencies.

posite coatings prepared under different ultrasonic frequencies with the same ultrasonic power of $200 \mathrm{~W}$. Ultra-

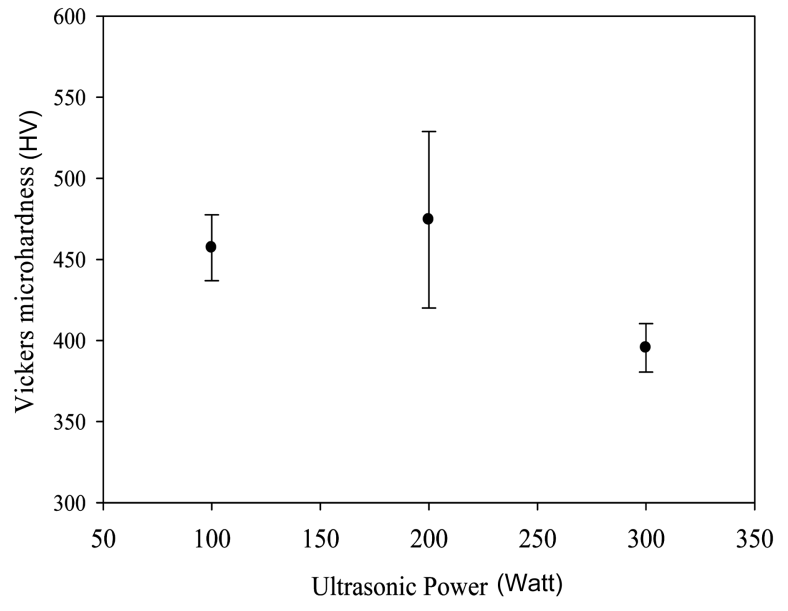

Fig. 5. Vickers microhardness of Ni-SiC composite coatings prepared at $38 \mathrm{kHz}$ ultrasonic frequency with different ultrasonic powers.

sonicated conditions having $38 \mathrm{kHz}$ frequency and 200 watt power (as shown in Fig. 2(C)) has shown the better dispersion of $\mathrm{SiC}$ compared with those of higher frequency (Fig. 2(D)) and lower frequency (Fig. 2(B)).

Fig. 3 shows the EDX spectrum of black spot at the cross-section of the sample as shown in Fig. 2(C). This also confirms that the $\mathrm{SiC}$ particles were successfully incorporated in the Ni matrix in presence of ultrasound.

Vickers microhardness of Ni-SiC composite coatings prepared under different ultrasonic frequencies is given in Fig. 4. Vickers microhardness was found to be increased at the frequency of $38 \mathrm{kHz}$ compared to those of $24 \mathrm{kHz}$ and $78 \mathrm{kHz}$ within the same ultrasonic power of 200 watt 


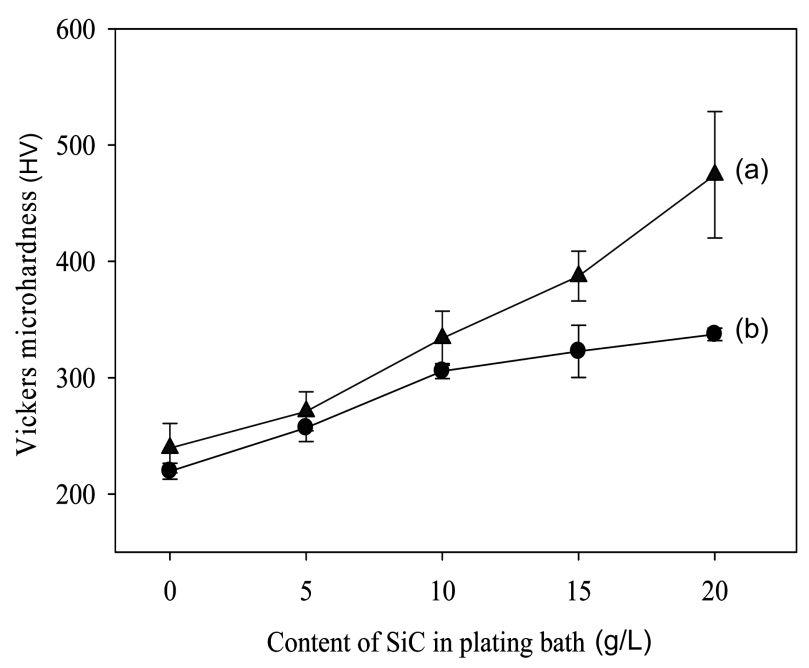

Fig. 6. Vickers microhardness of $\mathrm{Ni}-\mathrm{SiC}$ composite coatings prepared by different contents of $\mathrm{SiC}$ in plating bath; (a) with and (b) without ultrasound.

in each, for $20 \mathrm{~g} / \mathrm{L}$ of $\mathrm{SiC}$ in plating bath. It is due to the homogeneously dispersion of nano particles in the $\mathrm{Ni}$ matrix as well as increase in number of nucleation sites by inhibition of nickel grain growth at $38 \mathrm{kHz}$ ultrasonic frequency. Increasing the ultrasonic power from 100 watt to 200 watt also increased the microhardness but further increasing the ultrasonic power to 300 watt disturbed the oriented deposition and content of $\mathrm{SiC}$ in the composite leading to the decrease microhardness as shown in Fig. 5.

Fig. 6 shows the comparative effect on microhardness of composite coatings prepared at different contents of $\mathrm{SiC}$ in plating bath. In all ranges of $\mathrm{SiC}$ in plating bath, ultrasonicated samples ever shown the better microhardness than those of non-ultrasonicated samples.

XRD patterns of Ni-SiC nano composites are shown in Fig. 7. It is apparent that the diffraction pattern of the pure Ni deposit is characterized by an intense (200) diffraction line corresponding to a (100) texture. The preferred (200)

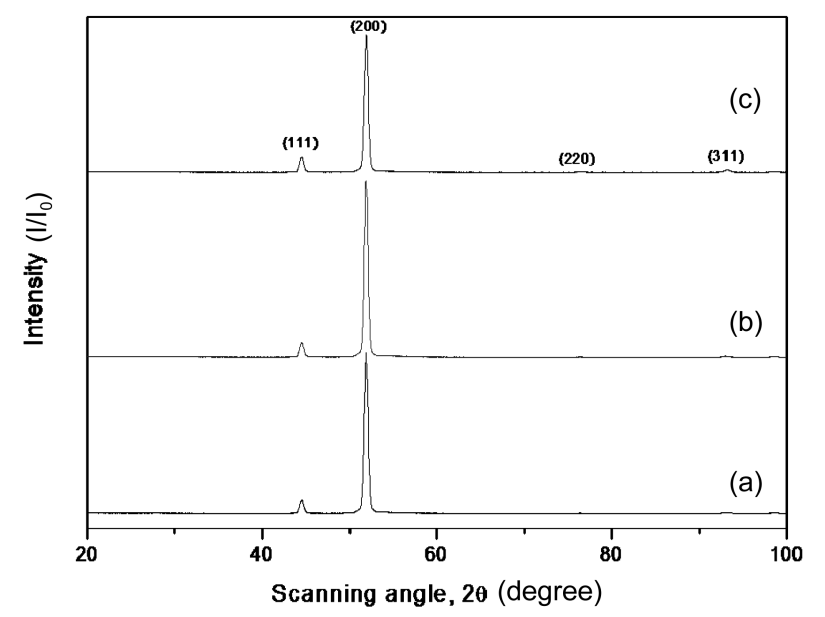

Fig. 7. XRD spectrum of pure $\mathrm{Ni}$ and $\mathrm{Ni}-\mathrm{SiC}$ composite coatings; (a) pure $\mathrm{Ni}$, (b) Ni-SiC without ultrasound treatment and (c) $\mathrm{Ni}-\mathrm{SiC}$ with ultrasound treatment.

peak intensity has been decreased in ultrasonicated sample than that of pure $\mathrm{Ni}$ and $\mathrm{Ni}-\mathrm{SiC}$ nano composite prepared without ultrasound. It is the evident that the change in orientation patterns of deposit from preferred to the random orientations was occurred by the influence of ultrasound. The decrease in (200) peak intensity of nickel composite represents the decrease in ductility properties of the composite. On the other hand, the decrease in ductility of composite means the increase in microhardness properties, which is also one of the goals of this experiment.

Wear tracks of the Ni-SiC composite coatings prepared in presence of ultrasound show less deep scars compared to that of non-ultrasonicated sample as shown in Fig. 8(A) and Fig. 8(B). From these results, it seems that the bonding strength between the agglomerated particles and the Ni matrix was not strong enough as compared to that between the uniformly dispersed particles and the nickel matrix. As a result, these agglomerated particles were removed at first from the coating surface in a first few
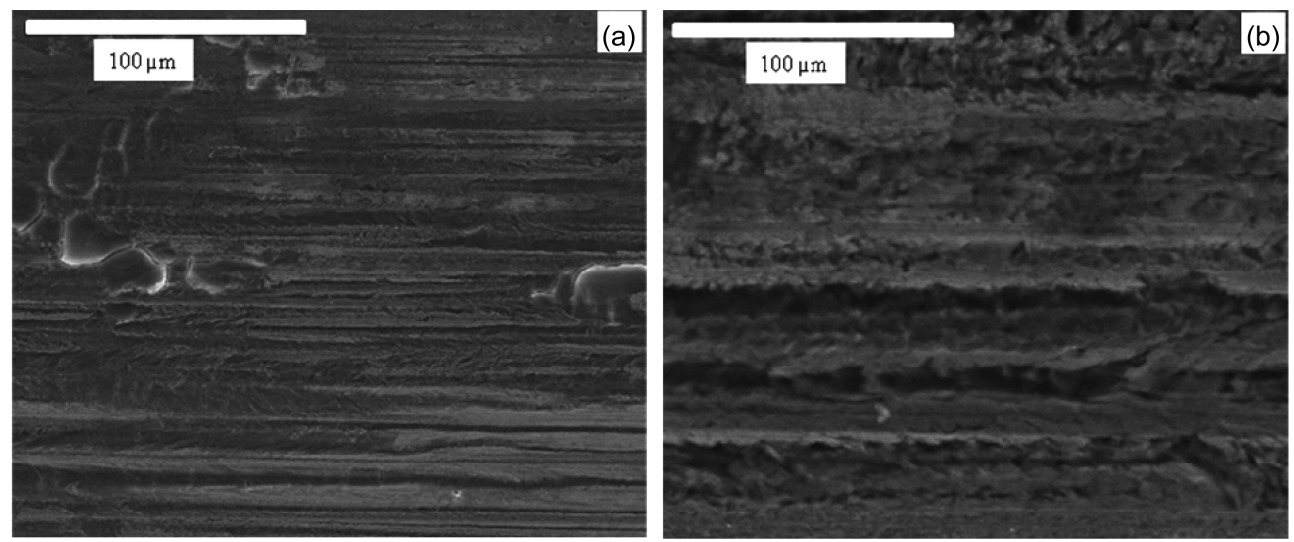

Fig. 8. Wear tracks of Ni-SiC composite coatings; a) ultrasonicated sample and b) non-ultrasonicated sample. 


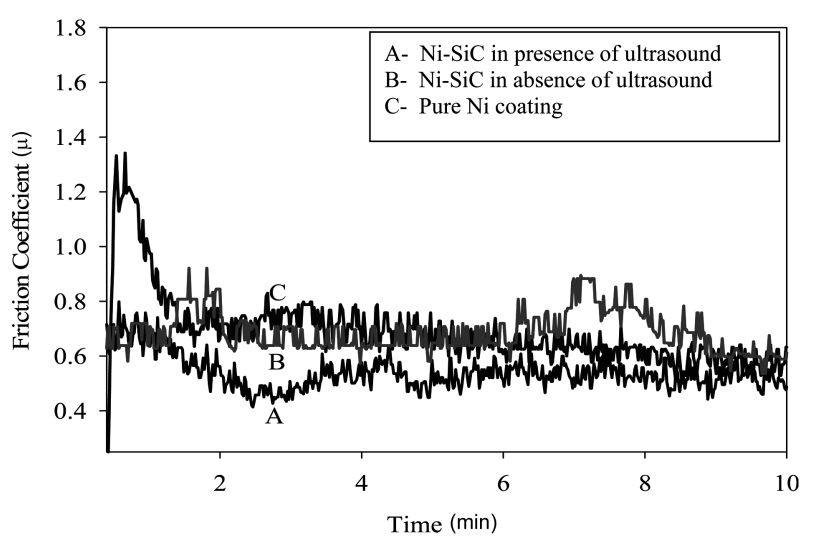

Fig. 9. Friction coefficients of pure $\mathrm{Ni}$ and $\mathrm{Ni}-\mathrm{SiC}$ composite coatings.

runs by the counter body, and were transferred to the counter surface. Hence, these adhesively transferred wear debris on counter ball had probably acted as a new counter surface for the further wear mode. Since $\mathrm{SiC}$ particles are harder, with the new counter surface might penetrate the inside of the coating more deeply. This is the reason for the larger wear scar depth of this coating.

Friction coefficients for the Ni-SiC composite coatings measured simultaneously during wear test are shown in Fig. 9. Friction coefficient of the composite coating prepared ultrasonic condition is less than that of pure $\mathrm{Ni}$ and $\mathrm{Ni}-\mathrm{SiC}$ composite prepared without ultrasound.

\section{Conclusion}

Ni-SiC nano composites were fabricated by electrodeposition technique with an aid of ultrasound. The composite prepared under ultrasonic condition exhibited finer grain, reduced particle agglomeration, and increased microhardness as compared to conventional electrodeposition without ultrasonic condition. The synergistic combination of superior wear resistance and improved microhardness of Ni-SiC composite coatings were obtained in ultrasonicated conditions. Hence, ultrasonic electrodeposition process has been proven better condition for the fabrication of composite coatings than that of conventional electrodeposition process without ultrasound.

\section{Acknowledgement}

This research was supported by Ministry of Knowledge Economy, Korea (Grant: Korea evaluation institute of industrial technology; 10033293).

\section{References}

1. A. F. Zimmerman, G. Palumbo, K. T. Aust, U. Erb, Mater. Sci. and Eng., A 328, 137 (2002).

2. Y. Boonyongmaneerat, K. Saengkiettiyut, S. Saenapitak, S. Sangsuk, Surf. Coat. Technol., 203, 3590 (2009).

3. L. Wang, Y. Gao, Q. Xue, H. Liu, T. Xu, Mater. Sci. Eng. A, 390, 313 (2005).

4. H. Gul, F. Kilic, S. Aslan, A. Alp, H. Akbulut, Wear, 267, 976 (2009).

5. S. Spanou, E. A. Pavlatou, N. Spyrellis, Electrochim. Acta, 54, 2547 (2009).

6. B. S. Xu, H. Wang, S. Dong, B. Jiang, W. Tu, Electrochem. Commun., 7, 572 (2005).

7. P. Gyftou, M. Stroumbouli, E. A. Pavlatou, P. Asimidis and N. Spyrellis, Electrochim. Acta, 50, 4544 (2005).

8. K. H. Hou, M. D. Ger, L. M. Wang, S. T. Ke, Wear, 253, 994 (2002).

9. M. R.Vaezi, S. K. Sadrnezhaad, L. Nikzad, Physicochem. Eng. Aspects, 315, 176 (2008).

10. H. K. Lee, H.Y. Lee, J. M. Jeon, Surf. Coat. Technol., 201, 4711 (2007).

11. P. Gyftou, E. A. Pavlatou, N. Spyrellis, Appl. Surf. Sci., 254, 5910 (2008).

12. N. S. Qu, K. C. Chan and D. Zhu, Scr. Mater., 50, 1131 (2004). 